\title{
POLYMORPHISM AND DIVISION OF LABOR IN THE DACETINE ANT ORECTOGNATHUS VERSICOLOR (HYMENOPTERA: FORMICIDAE)*
}

\author{
By Norman F. Carlin \\ Department of Organismic and Evolutionary Biology, \\ Harvard University, Cambridge, Mass. 02138
}

\section{INTRODUCTION}

The ants of the myrmicine tribe Dacetini exhibit a primary evolutionary trend from primitive epigaeic and subarboreal foragers to advanced cryptobiotic forms; in association with this trend are a number of secondary tendencies, including reduction in body size and mandible length, increasing specialization on collembolan prey, and loss of worker caste differentiation (Brown and Wilson 1959). The subarboreal and impressively long-mandibulate subtribe Orectognathiti, comprising the genera Orectognathus and Arnoldidris, occupies an intermediate position between the primitive polymorphic genus Daceton and the largely monomorphic higher subtribes Epopostrumiti and Strumigeniti. All but one of the twenty-nine known species of Orectognathus are monomorphic, the exception being $O$. versicolor, which possesses a distinctive major caste (Taylor 1977, 1979). Caste differentiation in this species is considered to have evolved secondarily, from the monomorphic generic stock (Brown and Wilson 1959).

The extreme polymorphism of Daceton armigerum, the only lower dacetine whose behavior has been studied, is put to work in an equally extreme division of labor (Wilson 1962). The minor workers are strictly limited to brood care tasks (in which they are aided by callows of larger castes), and to regurgitation with other adults. Small medias forage widely and actively, but larger medias and majors tend to rest in "way-stations" some distance from the nest. These large workers take prey away from returning smaller foragers, bringing it into the nest themselves, so that little prey is carried back by those that hunt for it. The species takes a broad variety of prey items; it has been suggested that the dietary specialization on collembolans seen in higher dacetines might account for their

\footnotetext{
*Manuscript received by the editor December 1, 1981.
} 
surrendering the polymorphism and polyethism of Daceton (Wilson 1971).

Orectognathus versicolor, as the sole polymorphic intermediate dacetine, is of special interest for polyethism analysis. The species is also an easy one to study, its slow-moving habits and small colony size making possible the recording of nearly every behavioral act performed by each individual worker. The minor workers possess the same long, slender mandibles, with pointed apical teeth, that their congeners bear. Majors, however, have massive, relatively short mandibles, with apical teeth thick, blunt and recessed; their large occipital lobes contain disproportionately developed mandible adductor muscles (figs. 1 and 2). In mandible allometry, at least, this species may be the most exaggeratedly polymorphic of all dacetines. The division of labor by which such morphologically divergent forms are utilized, particularly since the major caste is a secondary development, may shed light on the advantages of specialized castes in the context of dacetine evolution. To what use are the singular majors put? Does the polyethism of $O$. versicolor in any way resemble that of Daceton, or is it entirely independent? Has the return to polymorphism been accompanied by a return to the polyphagy of Daceton, or is $O$. versicolor a collembolan specialist, as the rest of its genus is thought to be (Brown 1953)? An opportunity to address these questions in the laboratory arose when Bert Hölldobler brought a live queenright colony of these ants from North Queensland, Australia; the results of observation of this colony are reported below.

\section{Materials AND MethodS}

The $O$. versicolor colony was settled in a glass test tube $(2 \mathrm{~cm}$ in diameter), with water trapped at its end behind a tight cotton plug. The tube was placed in a plaster-floored clear plastic container (18 $\mathrm{cm}$ by $12 \mathrm{~cm}$ by $6 \mathrm{~cm}$ ), and a dissecting microscope was set over it on a moveable mount to permit viewing of ants both inside the nest tube and out on the container floor. A total of 45 hours of observation were made over a period of five weeks, during which 7,891 separate behavioral acts were recorded. Estimation of the completeness of caste behavior repertories was made by fitting the data to a lognormal Poisson distribution, following the method of Fagen and Goldman (1977). The ants were offered various food 

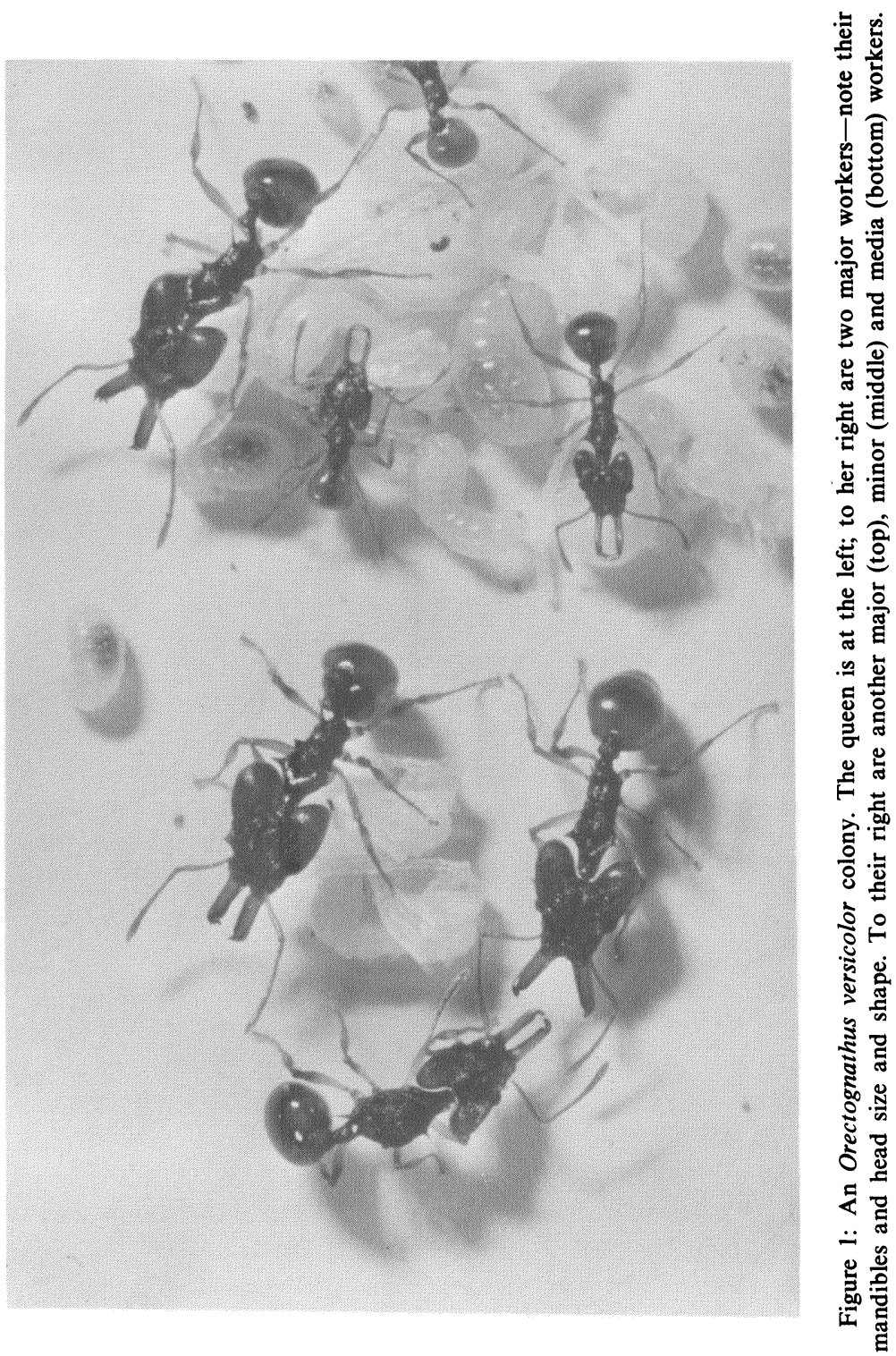
items; to examine their defensive behavior, small Solenopsis invicta workers were introduced into their container.

The two morphological castes were easily distinguished on the basis of mandible thickness. In order to record division of labor among individuals of different sizes, yet similar proportions-so critical in weakly allometric species such as Daceton-the minor workers were arbitrarily divided into small and medium size classes, also distinguishable by eye. For convenience, these subcastes will be referred to as "minors" and "medias", as in Wilson 1978. By-eye assignment of caste to preserved specimens, subsequently measured, produced the following definitions of size classes and castes: minors, head width less than $1.12 \mathrm{~mm}$; medias, head width between 1.13 and $1.64 \mathrm{~mm}$; majors, head width greater than $1.65 \mathrm{~mm}$. After some initial die-off, the colony contained fifty-two adults for the duration of the study: one queen, thirty minors, fifteen medias and six majors.

\section{RESULTS}

O. versicolor is in fact polyphagous. Live flightless Drosophila were readily accepted, and young were successfully raised on this diet. The ants also accepted Drosophila larvae, and, not surprisingly, collembolans. (Alternative foods were not offered simultaneously to test preferences; however, most collembolan specialist species would not touch other prey even if starving.) The same colony had been fed mealworm and cockroach fragments, various diptera and honeywater in Australia (B. Hölldobler, pers. comm.).

The ethogram or behavioral catalogue of workers and queen is presented in table 1, which gives both numbers of individual acts performed and the relative frequencies of acts in the total repertory of each caste. The colony repertory consisted of twenty-seven categories of behavior. (Worker regurgitation with the queen was added as a twenty-eighth because it was seen twice during preliminary observations, though never during the study.) The observed minor and media repertories both contained twenty-seven behavior categories; the observed major repertory contained twenty-four. Using the Fagen-Goldman statistical method, the estimated total repertory size for minors - the observed repertory plus an estimate of the number of categories not observed-was calculated to be twenty-nine, with a $95 \%$ confidence interval of $(27,32)$ acts. The 


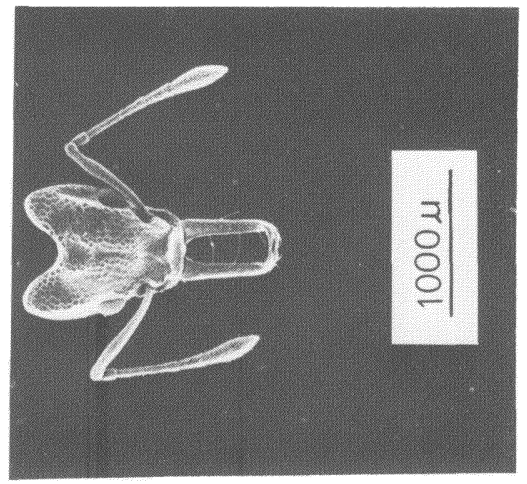

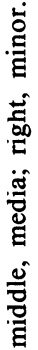

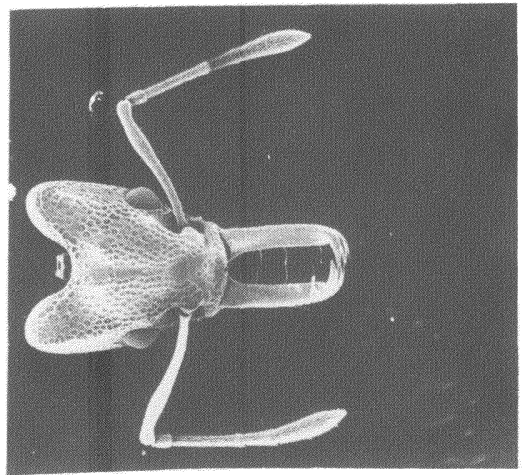

苂

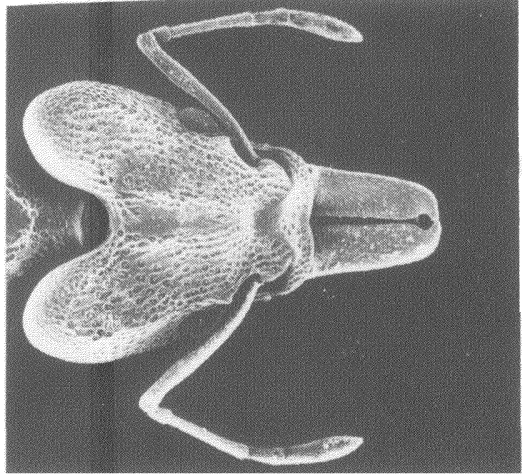

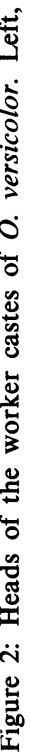


Table 1: Ethogram of Orectognathus versicolor. The values given are numbers of individual acts performed by members of each caste. In parentheses are given relative frequencies of performance of each act in the total repertory of the caste.

\begin{tabular}{|c|c|c|c|c|}
\hline & Minor & Media & Major & Queen \\
\hline Self-groom & $1370(.3481)$ & $845(.2996)$ & $462(.4306)$ & $45(.7258)$ \\
\hline Allogroom minor & $437(.1110)$ & $93(.0330)$ & $18(.0168)$ & $1(.0161)$ \\
\hline Allogroom media & $144(.0366)$ & $224(.0794)$ & $16(.0149)$ & 0 \\
\hline Allogroom major & $100(.0254)$ & $52(.0184)$ & $15(.0140)$ & 0 \\
\hline Allogroom queen & $27(.0069)$ & $20(.0071)$ & $8(.0075)$ & 1 \\
\hline $\begin{array}{l}\text { Regurgitation } \\
\text { with minor }\end{array}$ & $48(.0122)$ & $15(.0053)$ & $3(.0028)$ & $2(.0323)$ \\
\hline with media & $10(.0025)$ & $21(.0074)$ & $7(.0065)$ & 0 \\
\hline with major & $13(.0033)$ & $2(.0007)$ & $2(.0019)$ & 0 \\
\hline with queen & 0 & 0 & 0 & 1 \\
\hline $\begin{array}{l}\text { Carry or manipu- } \\
\text { late egg }\end{array}$ & $4(.0010)$ & $2(.0007)$ & $1(.0009)$ & 0 \\
\hline Lick egg & $18(.0046)$ & $5(.0018)$ & $1(.0009)$ & $1(.0161)$ \\
\hline $\begin{array}{l}\text { Carry or manipu- } \\
\text { late larva }\end{array}$ & $53(.0135)$ & $37(.0131)$ & $2(.0019)$ & 0 \\
\hline Lick larva & $602(.1529)$ & $520(.1844)$ & $155(.1445)$ & $9(.1425)$ \\
\hline $\begin{array}{l}\text { Regurgitate with } \\
\text { larva }\end{array}$ & $4(.0010)$ & $11(.0039)$ & $2(.0019)$ & 0 \\
\hline $\begin{array}{l}\text { Feed larva solids } \\
\text { Carry or manipu- }\end{array}$ & $19(.0048)$ & $20(.0071)$ & 0 & 0 \\
\hline late pupa & $7(.0018)$ & $9(.0032)$ & $6(.0056)$ & 0 \\
\hline Lick pupa & $54(.0137)$ & $63(.0223)$ & 18 ( .0168) & 0 \\
\hline Forage & $364(.0925)$ & $356(.1262)$ & $126(.1174)$ & 0 \\
\hline Capture prey & $19(.0048)$ & $26(.0092)$ & $2(.0019)$ & 0 \\
\hline $\begin{array}{l}\text { Return prey to } \\
\text { nest }\end{array}$ & $19(.0048)$ & $6(.0021)$ & 0 & 0 \\
\hline Process prey & $45(.0114)$ & $25(.0089)$ & $4(.0037)$ & 0 \\
\hline Eat prey & $132(.0335)$ & 109 (.0387) & $19(.0177)$ & $2(.0323)$ \\
\hline Guard & $313(.0795)$ & $280(.0993)$ & $186(.1733)$ & 0 \\
\hline $\begin{array}{l}\text { Manipulate nest } \\
\text { material }\end{array}$ & $67(.0170)$ & $13(.0046)$ & $2(.0019)$ & $1(.0161)$ \\
\hline Lick tube wall & $27(.0069)$ & $26(.0092)$ & $12(.0112)$ & $1(.0161)$ \\
\hline $\begin{array}{l}\text { Remove refuse } \\
\text { (in tube) }\end{array}$ & $9(.0023)$ & $1(.0004)$ & 0 & 0 \\
\hline $\begin{array}{l}\text { Remove refuse } \\
\text { (out of tube) }\end{array}$ & $12(.0030)$ & $19(.0067)$ & $4(.0037)$ & 0 \\
\hline Carry dead ant & $19(.0048)$ & $20(.0071)$ & $2(.0019)$ & 0 \\
\hline Total \# acts & $3936(1.0 \quad)$ & $2820(1.0)$ & $1073(1.0 \quad)$ & $62(1.0$ \\
\hline \# categories & 27 & 27 & 24 & 8 \\
\hline \# individuals & 30 & 15 & 6 & 1 \\
\hline
\end{tabular}


estimated total repertory size for medias was twenty-eight, the $95 \%$ confidence interval $(27,33)$; for majors, twenty-seven, with a confidence interval of $(24,37)$.

Minor and media workers engaged in the same tasks with essentially similar frequencies, while majors, with a smaller repertory, also performed certain acts with quite different frequencies. Self-grooming was the commonest act in all castes. Allogrooming and regurgitation occurred freely among all castes, with a tendency among minors and medias to interact with their own class. After self-grooming, brood care and foraging were the most frequently performed acts in the minor and media repertories. An ant was scored as "foraging" any time it left the nest tube - an act that does not necessarily signify hunting for food. Though majors did "forage" by this definition, they captured almost no prey and returned none to the nest. "Processing", in which workers tore at, dismembered and occasionally stung prey that had been brought inside the tube, was rarely performed by majors, despite the seeming usefulness of their heavy mandibles for such a task.

The province of the majors was "guarding": walking to the tube mouth and facing outward without setting foot on the container floor; after self-grooming, it was their most frequent act. A guarding ant might station itself at the opening for less than a minute or up to half an hour. That this is in fact a defensive behavior will be shown below. Minors and medias also guarded in large numbers, but less frequently than they foraged or attended brood.

Nest maintenance was undertaken almost exclusively by the small size classes. Carrying refuse down the tube, to be dropped inside or just outside the entrance, was defined as "in-tube refuse removal", while carrying trash out to corner refuse piles on the container floor (to which dead ants were also brought) was defined as "out-of-tube refuse removal." "Manipulation of nest material", that is, of the fibers of the cotton plug, may not be an actual maintenane behavior used in natural colony sites (under stones, in rotting wood); similarly, ants may lick the tube wall only to drink condensation on the glass, and not exhibit any such behavior in the wild.

The division of labor among minor and media size classes, and the role of the major caste, were better elucidated by constructing polyethism curves, depicting the percent contributions of each caste to the total colony performance of behaviors (figs. 3 and 4). For simplicity, certain behavioral categories from the ethogram were 

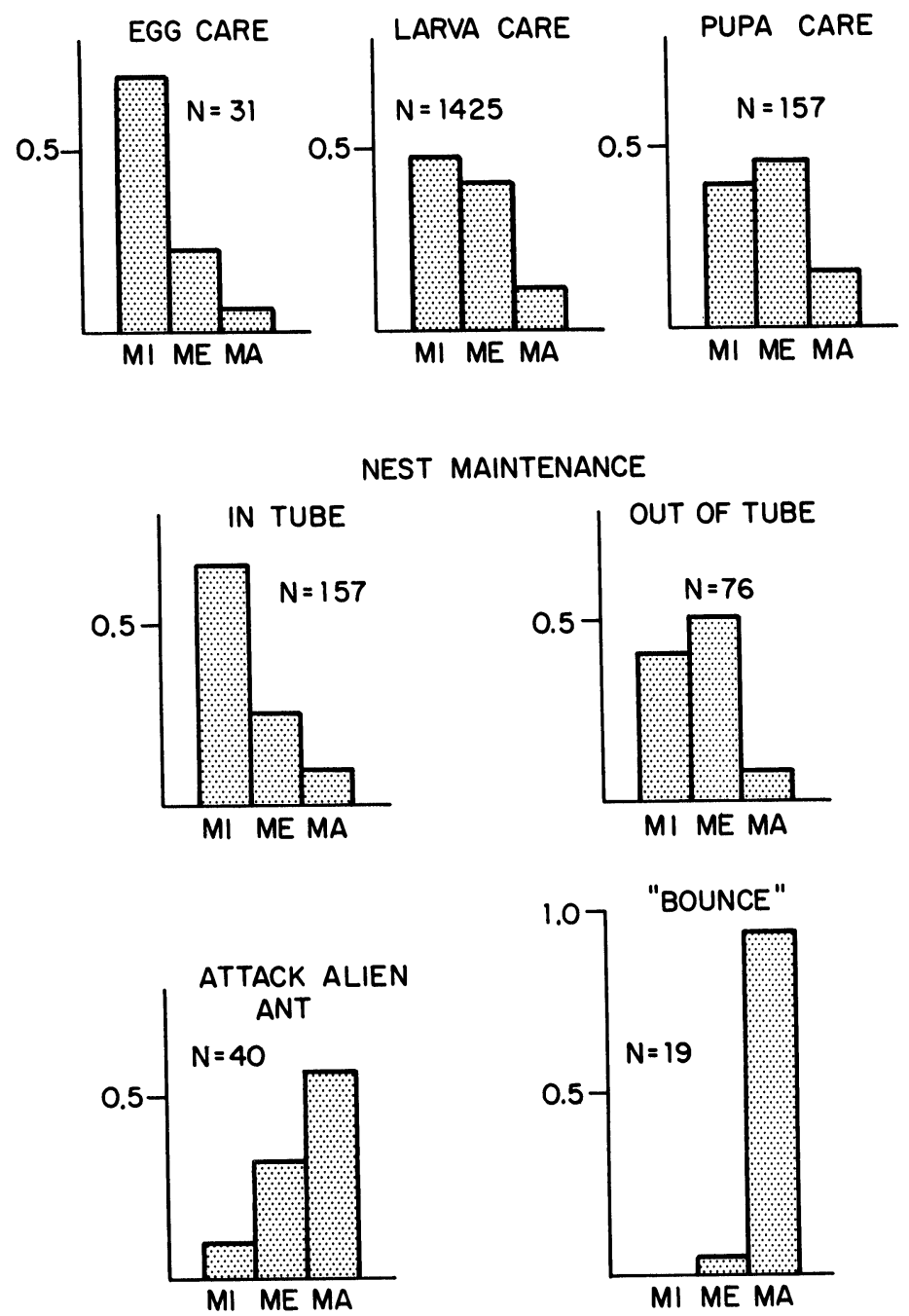
combined, so that the polyethism curves indicated represent groups of tasks. There was a tendency to divide those tasks performed primarily by small workers among the size classes on the basis of size of objects handled and task location (fig. 3). Minors performed most in-nest maintenance; medias performed somewhat more outof-nest maintenance than did minors. Minors contributed most to egg care. While both size classes attended larvae and pupae, minors contributed less to larva care than to egg care, still less to pupa care, medias compensating by putting more effort into care of larger brood.

On the introduction of Solenopsis workers, the function of the guarding majors became apparent. As an alien ant approached, they spread their mandibles about $120^{\circ}$ apart. When the tip of the invader's head was within a major's gape, the mandibles snapped shut, pinching the invader's extremity with sufficient force to shoot it away like a squirted watermelon seed. This very effective defensive behavior, which was termed "bouncing", kept nearly all alien ants from gaining entrance to the nest. Only majors, with their large mandibles and powerful adductor muscles, are equipped to do this properly (fig. 3). Major bouncers, guarding the tube mouth, could propel invaders backward for up to 8 or $9 \mathrm{~cm}$; a single large media was able to bounce an invader, but not for very far. The blunt apical teeth of majors pinched but did not penetrate-invaders were not injured at all, just repelled. Ants of all castes struck at invaders that managed to get past the bouncers, majors contributing most to these attacks (fig. 3). They did not attempt to bounce a successful invader, but instead grabbed it in their mandibles and dragged it out, unharmed, after which they resumed the guarding position.

Minor and media workers foraged in nearly equal numbers, but did not participate equally in predatory behavior. More prey was

Figure 3: Polyethism curves of nest-centered activities, showing the percent contribution of workers of each caste to the total colony performance of given tasks. $\mathrm{MI}=$ Minor worker $\mathbf{M E}=$ media; $\mathrm{MA}=$ Major. Some tasks are composites of several behavior categories in the ethogram (table 1): Egg care = carry or manipulate egg + lick egg; larva care $=$ carry or manipulate larva + lick larva + regurgitate with larva + feed larva solid food; pupa care $=$ carry or manipulate pupa + lick pupa. In-tube nest maintenance $=$ manipulate nest material + lick tube wall + remove refuse (in tube); out-of-tube maintenance $=$ remove refuse $($ out of tube) + carry dead ant. Attacking alien ants and "bouncing" described in the text. 
captured by medias, while most was returned to the nest by minors (fig. 4); minors also contributed most to processing, an in-nest activity. Medias brought back only about one-fifth of the prey they caught. It is possible that minors play a role similar to that of majors in Daceton, bringing in food captured by foragers of another caste, not themselves hunting as actively. However, minors were never observed to take prey away from medias. They simply retrieved prey that medias had dropped, a rather slipshod method of transferring
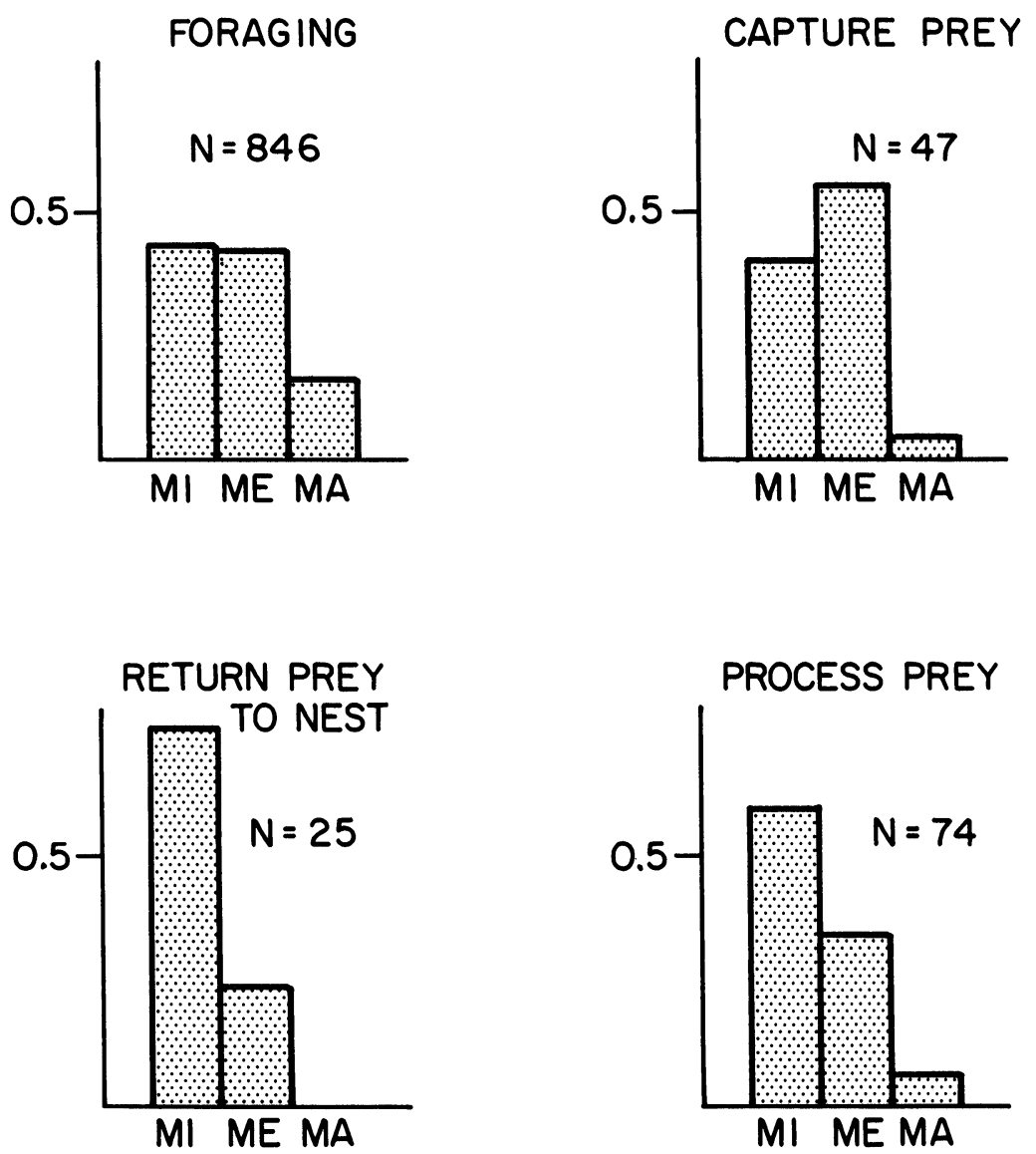

Figure 4: Polyethism curves of predatory behavior. Behavior categories are the same as in the ethogram (table 1). 
food. Alternatively, the medias may have been killing flies as trespassers approaching the nest too closely, rather than as prey, whereupon minor foragers picked up the remains. Majors could not leave their post at the entrance to engage in defense of the nest vicinity without exposing the opening to invaders. Besides, the bouncing strategy would be less effective in the open; it requires an invader to walk directly into the defender's mandibles.

Callow workers being easily recognizable by their lighter body color, the repertories of age groups within castes were examined for age polyethism. Callows exhibited fewer categories of behavior than older adults. As in Daceton and many other ant species (Wilson 1971) they tended to concentrate on safe, in-nest tasks. Callow majors were notably more involved in brood care than older majors.

As Brown (1957) had reported the genus to be nocturnal, observations were taken both during the day and, under red light, at night. Most foraging did indeed occur at night, but the ants engaged in a greater total number of acts, in more behavior categories, during the day, due to a diurnal rise in brood care and in-nest maintenance activity. This result suggests that more complete behavioral repertories can be compiled in the laboratory by studying ants during their periods of "inactivity", when they are not investing so much of their effort in foraging.

\section{Discussion}

Polymorphic workers of Orectognathus versicolor exhibit, all in all, a fairly elementary division of labor: Minor and media repertories are predictably similar, while majors constitute a distinct caste on behavioral as well as morphological grounds. The minor size class contributes most to in- and near-nest activity, including prey retrieval; the medias have a somewhat greater tendency to perform out-of-nest tasks and care for large brood; and the majors defend.

Even if the medias are capturing prey and dropping it for minors to bring in, the resemblance to the polyethism pattern of Daceton is convergent at most. Daceton majors, not minors, return prey to the nest; Orectognathus majors are bouncers. Daceton minors are restricted to brood care, while medias perform in-nest processing and refuse disposal (Wilson 1962); Orectognathus minors attend all these tasks. The polyethism of $O$. versicolor is entirely unrelated to that of Daceton, having apparently arisen de novo along with its secondary polymorphism. 
O. versicolor has also returned to polyphagy along with polymorphism, consistent with the general correlation seen in its tribethe only higher dacetine to return secondarily to polymorphism, Strumigenys loriae, is also polyphagous (Brown and Wilson 1959). The degree of dietary specialization in the genus Orectognathus as a whole may have been overestimated: A colony of the monomorphic species $O$. clarki, collected by Hölldobler in New South Wales, Australia, was maintained at a subsistance level on a diet of cockroach and mealworm fragments and honey-water (Hölldobler, pers. comm.). However, this colony did not thrive, while the $O$. versicolor colony on the same diet flourished, raising many new workers and even males. Clearly $O$. versicolor does take noncollembolan prey more readily; what is not clear is the causality behind this correlation. The polyethism of Daceton, at least, is associated with predatory behavior. I had speculated that the $O$. versicolor majors might serve as "arthropod millers", analogous to the seed-miller majors of Solenopsis geminata (Wilson 1978), their heavy mandibles used in processing a variety of prey with hard exoskeletons. Instead, they proved to be soldiers; perhaps in defending so efficiently, they somehow free smaller workers to forage for different prey items, which might require wandering further from the nest vicinity than would foraging for abundant collembolans. But this reasoning is vague at best and requires further investigation.

It is the major caste and its role that make this species noteworthy, among dacetines and among ants in general. "Bouncing" is a new kind of nest defense strategy, ideally suited for repelling enemies in a species whose modified mandibles, designed for impaling softbodied prey, are of no use in fighting. Minors and medias can be seriously injured, in attacking invaders they are unable to harm. Bouncing minimizes contact between defenders and invaders, expelling the latter without a fight. Presumably, large workers of the monomorphic species ancestral to $O$. versicolor, modifying slightly the prey-capturing strike to pinch an extremity rather than pierce, found themselves able to shoot enemies away for short distances. This defense was so advantageous that heavier mandibles with blunt, pinching teeth were strongly selected for, along with guarding behavior, eventually producing the modern majors. Generally, major castes in ants serve as soldiers. In a few species, they specialize in physically blocking the nest opening with their large heads 
(certain Camponotus species, Wilson 1971; Zacryptocerus texanus, Creighton and Gregg 1954). In Zacryptocerus varians, which also has modified mandibles useless for fighting, majors use their saucershaped heads to actively "bulldoze" invaders out (Wilson 1976). Major bouncers of $O$. versicolor are unique in using their mandibles to expel invaders without injury.

To produce a caste so specialized for this form of defense, colonies must be under considerable pressure from ant species approximately the same size as Solenopsis (it would be hard to shoot a larger ant). When bouncing fails, majors do attack in a more conventional manner, as is seen in their response to successful invaders. (Bouncing might accidentally shoot these further into the nest.) It has recently been shown (Hölldobler 1982) that majors also respond to alarm-recruitment pheromones.

Other dacetines, including $O$. clarki, the monomorphic species most closely related to $O$. versicolor, often post "sentinels" at nest entrances (Brown 1953; he also observed occasional "retrosalience", an ant striking at a hard surface and shooting itself backward-the same motor act as bouncing, but apparently accidental). The $O$. clarki colony, when subjected to size class polyethism analysis, revealed a weak division of labor very similar to that of $O$. versicolor minors and medias. It is easy to conceive of these size classes as the "primitive caste" (Wilson 1980) typifying the monomorphic ancestor of both species, from which increasing defensive specialization turned the sentinels still seen in the former into the bouncers of the latter.

\section{ACKNOWLEDGMENTS}

I am very grateful to Dr. B. Hölldobler and Dr. E. O. Wilson, for the use of materials and the suggestion of methods, for helpful advice, for criticizing the manuscript, and for allowing me this entry into the insect societies. I would also like to thank Mark Moffett for suggestions, assistance, comments on the manuscript and moral support, Dr. R. Taylor for identifying the ants, David S. Gladstein for help with the repertory size estimations and polyethism curves, Dr. Hölldobler for the photograph in figure 1, Edward Seling for the electron photomicrographs, and Kathleen Horton for the word "bouncer".

This work was supported in part by grants from the National 
Science Foundation, \#8NS80-02613, and from the National Geographic Society, both to B. Hölldobler.

\section{REFERENCES}

Brown, W. J., JR.

1953. A revision of the dacetine ant genus Orectognathus. Mem. Queensland Mus. 13:84-104.

1957. A supplement to the revision of the dacetine ant genera Orectognathus and Arnoldidris, with keys to the species. Psyche 64(1):17-29.

Brown, W. L. JR. AND E. O. WILSON

1959. The evolution of the dacetine ants. Quart. Rev. Biol. 34(4):278-294.

Creighton, W. S. and R. E. GregG

1954. Studies on the habits and distribution of Cryptocerus texanus Santschi (Hymenoptera: Formicidae). Psyche 61(2):41-57.

FAGEN, R. AND R. Goldman

1977. Behavioral catalogue analysis methods. Anim. Behav. 25:261-274.

HÖLLDOBLER, B.

1982. Trail communication in the dacetine ant Orectognathus versicolor. Psyche 88:245-257.

TAYLOR, R. W.

1977. New ants of the genus Orectognathus, with a key to the known species. Austr. J. Zool. 25:581-612.

1979. New Australian ants of the genus Orectognathus, with summary description of the twenty-nine known species (Hymenoptera: Formicidae). Austr. J. Zool. 27:773-788.

WILSON, E. O.

1962. Behavior of Daceton armigerum (Latreille), with a classification of selfgrooming movements in ants. Bull. Mus. Comp. Zool. 127(7):403-421.

1971. The Insect Societies. Belknap Press of Harvard Univ. Press, Cambridge, Mass.

1976. A social ethogram of the Neotropical arboreal ant Zacryptocerus varians (Fr. Smith). Anim. Behav. 24:(2):354-363.

1978. Division of labor in fire ants based on physical castes (Hymenoptera: Formicidae: Solenopsis). J. Kansas Entom. Soc. 51(4):615-636.

1980. Caste and division of labor in leaf-cutting ants (Hymenoptera: Formicidae: Atta). Behav. Ecol. Sociobiol. 7:143-156. 

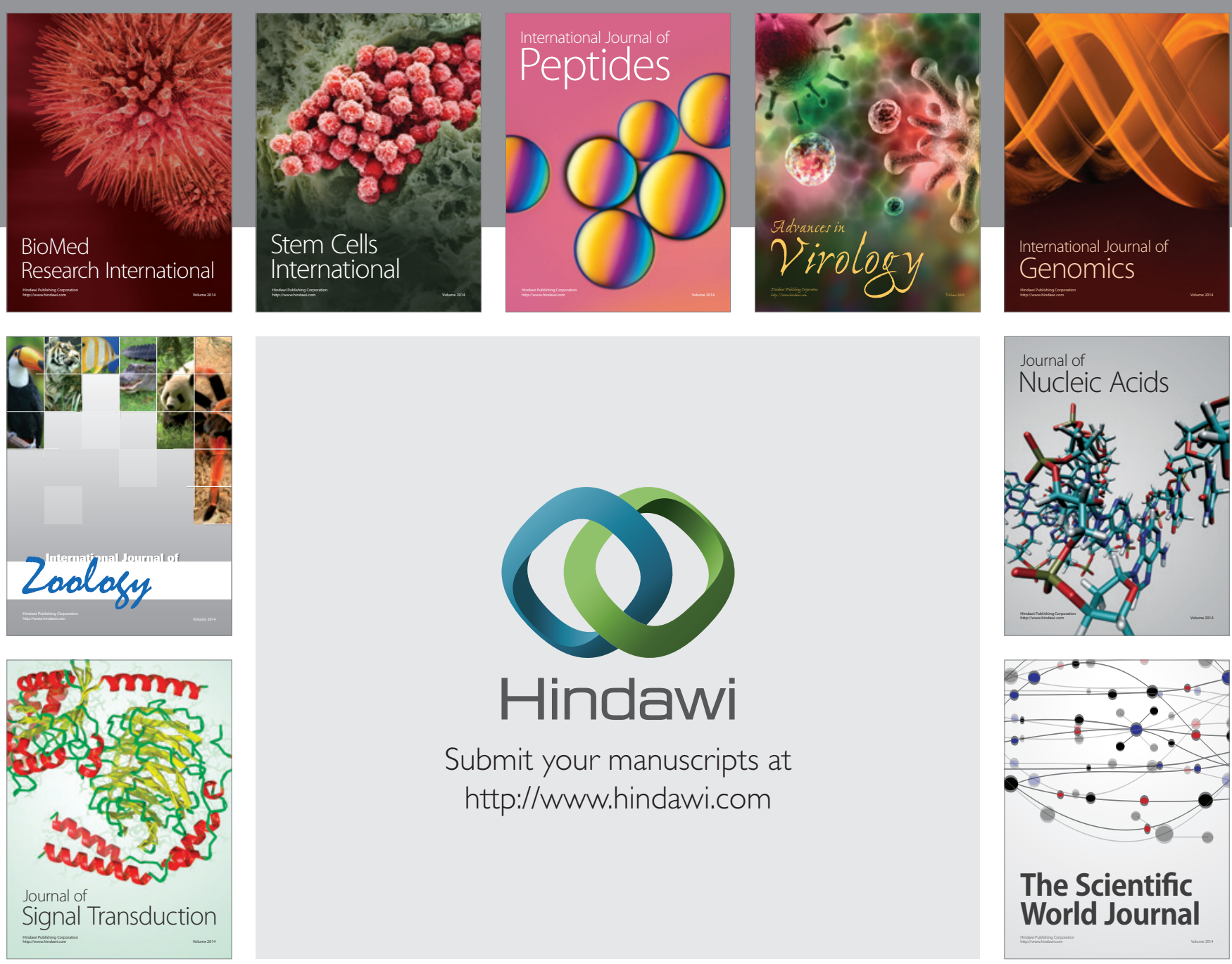

Submit your manuscripts at

http://www.hindawi.com
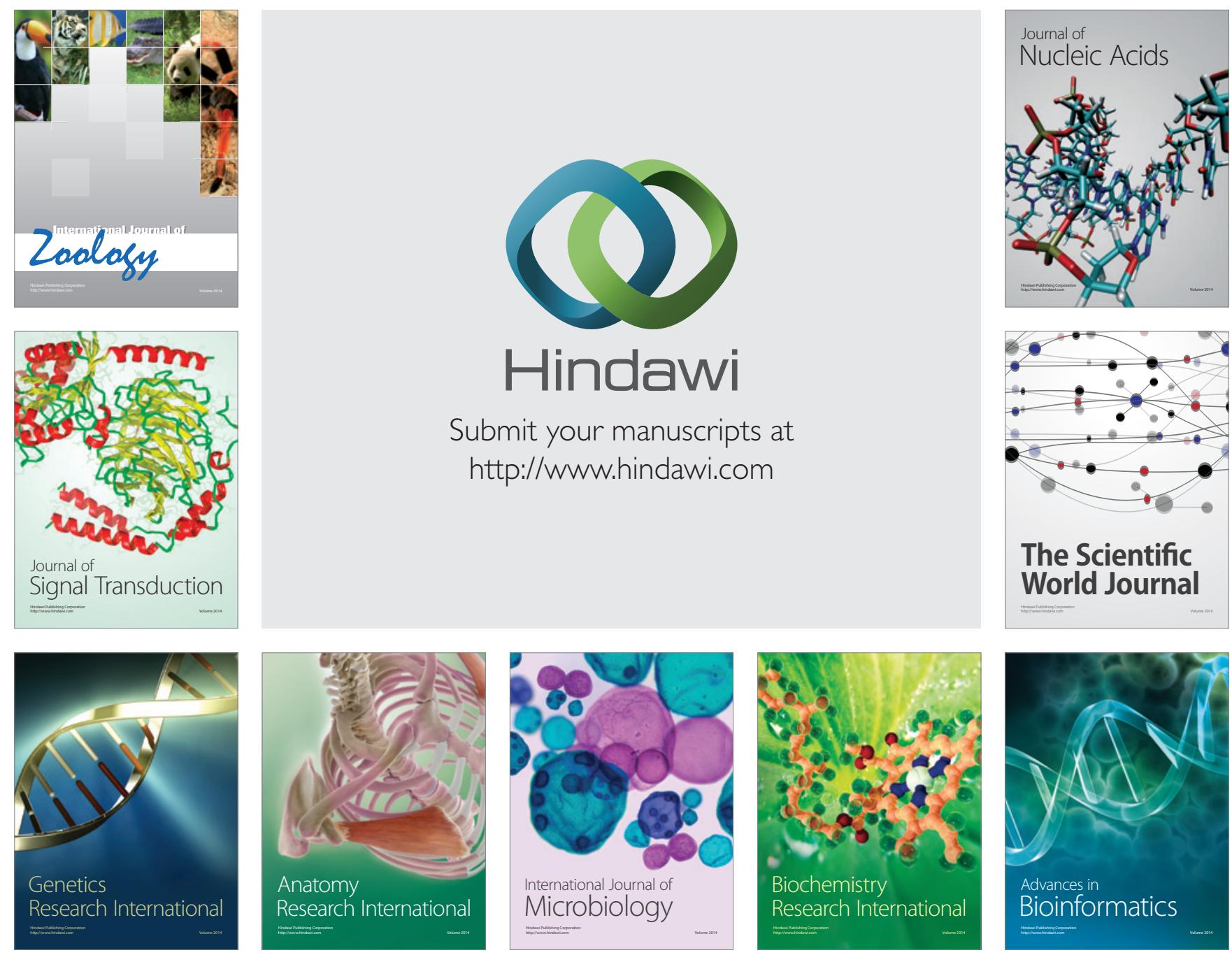

The Scientific World Journal
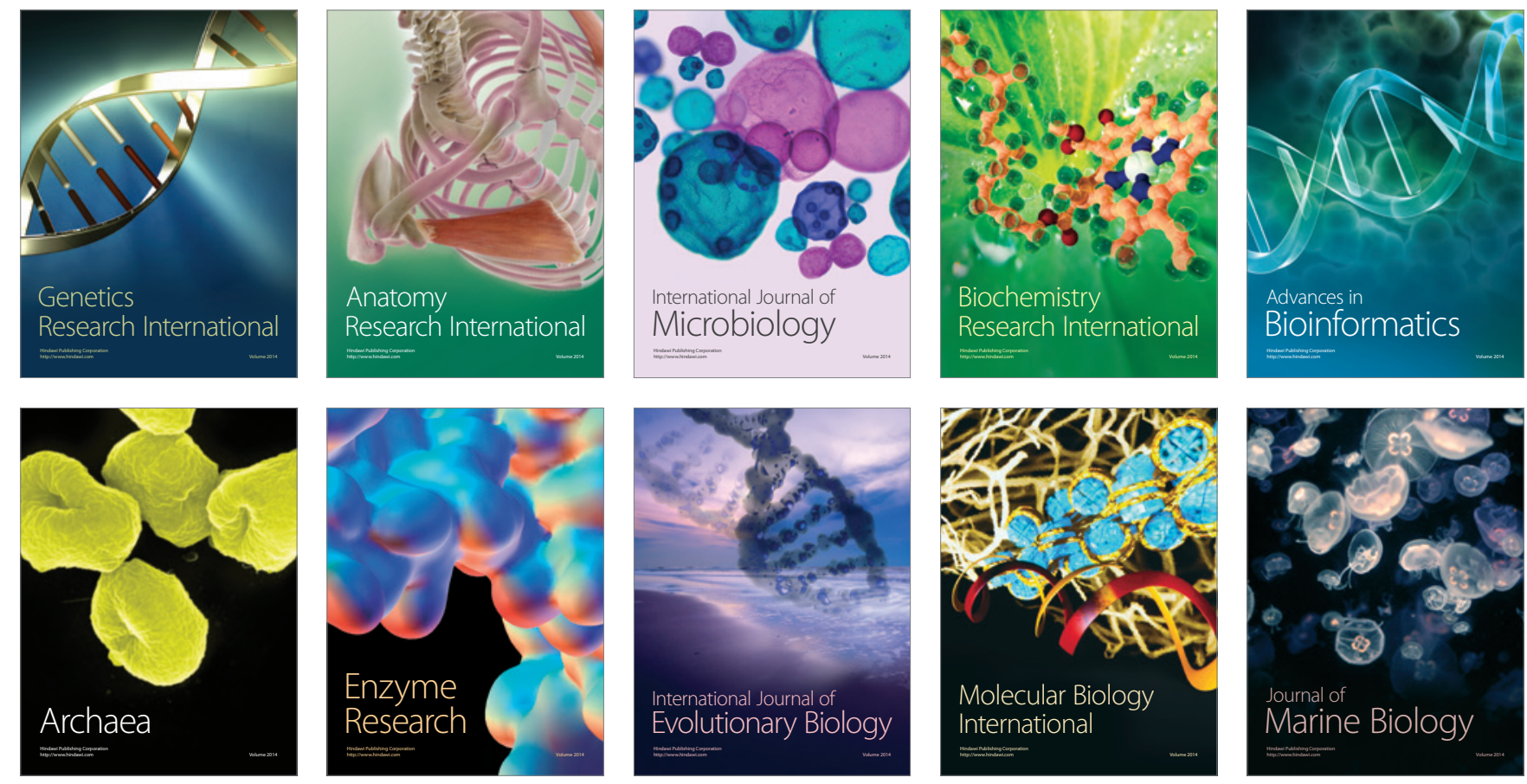